\title{
Entre silêncios e esquecimentos: o Museu do Homem Sergipano, Brasil (2009-2013)
}

\author{
Janaina Cardoso Mello ${ }^{1}$
}

\section{Resumo:}

O Museu do Homem Sergipano (MUHSE), vinculado à Pró-Reitoria de Extensão e Assuntos Comunitários da Universidade Federal de Sergipe (UFS), iniciou suas atividades em novembro de 1996, ocupando até 2013 um prédio histórico em Aracaju/SE/Brasil. Sua exposição de longa duração foi extraída do livro "Textos para a História de Sergipe" (1991). O museu encontrou sua vocação na ação educativa voltada para o público escolar (Nunes, 2010:70). Desde 02 de maio de 2011, o museu foi fechado à visitação em razão da deterioração dos edifícios. O objetivo desse trabalho, em meio ao processo de ressignificação pelo qual o MUHSE passa desde 2014, busca historicizar os processos desenvolvidos na instituição entre os anos de 2009 e 2013. Diante da nova proposta de redirecionamento museal, sobretudo da ressemantização da instituição, questiona-se de que forma a Nova Museologia ou a Museologia Social poderia servir como bússola para apontar o horizonte. Entre memória e esquecimento, não seria melhor realizar a salvaguarda do patrimônio com respeito e atenção à contribuição de discentes, docentes, visitantes, gestores e vizinhos ao espaço museal? O trabalho parte da observação participativa de documentos (Portarias e Resoluções institucionais) e ações no museu estudado, bem como das leituras de Mário Moutinho, Paul Ricoeur, Pierre Nora, dentre outros.

Palvras-chaves: museu; esquecimento; história; Museologia Social; ressignificação.

${ }^{1}$ Professora Doutora em História Social (UFRJ); Pós-Doutoranda em Estudos Culturais (UFRJ); Professora de História do Brasil do Departamento de Museologia da Universidade Federal de Sergipe (UFS). Coordenadora do Grupo de Estudos e Pesquisas em Memória e Patrimônio Sergipano (GEMPS/CNPq). janainamello@uol.com.br 


\begin{abstract}
:
The Museum of Man in Sergipe (MUHSE), linked to the Department of extension and Community Affairs at the Universidade Federal de Sergipe (UFS), began operations in November 1996, occupying up to 2013 a historic building in Aracaju/SE/Brazil. Your long-term exposure was extracted from the book "Texts for the history of Sergipe" (1991). The Museum found his vocation in educational actions aimed at school audiences (Nunes, 2010: 70). Since May 2, 2011, the Museum has been closed to visitors because of the deterioration of the buildings. The objective of this work, in the midst of the process of new signification whereby the MUHSE passes from 2014, seeks to historicize the processes developed at the institution between 2009 and 2013. Before the new proposal redirects, especially on the new semantics of the institution, wonders how the New Museology or Social Museology could serve as a compass to point the horizon. Between memory and oblivion, wouldn't it be better to make the safeguarding of heritage with respect and attention to the contribution of students, faculty, visitors, managers and neighbors to museum space? The work part of participatory observation of documents (institutional Ordinances and Resolutions) and actions at the Museum studied, as well as readings of Mário Moutinho, Paul Ricoeur, Pierre Nora, among others.
\end{abstract}

Keywords: Museum; oblivion; history; Social Museology; new signification.

Iniciando suas atividades em novembro de 1996, sendo nomeado Museu do Homem Sergipano (MUHSE)², a instituição

\footnotetext{
${ }^{2}$ Entre 1973 a 1976 há um conjunto de ações para a criação do Museu, quando então ele nasce como Museu de Antropologia - órgão suplementar da PROEXUFS, mas sem uma estrutura física. Com o Dec.08 - DPSA/DCS cria-se o setor de Antropologia que sob a liderança da professora Beatriz Góis Dantas realiza exposições itinerantes sobre a temática indígena e a cerâmica sergipana. $\mathrm{Na}$ década de 1980 o CULTART cede uma sala onde Hélia Maria de Paula Barreto, professora do Departamento de Ciências Sociais torna-se responsável pela Sala de Cultura Popular. Em poucos anos a sala é fechada e do final da década de 1980 ao início da década de 1990, a discussão sobre a criação de uma instância museológica se faz presente, e com as contribuições da professora Cristina Bruno cria-se o Núcleo Museológico, abrigado na sala do CCBS/UFS que passa a acondicionar as exposições itinerantes que anteriormente foram organizadas pela professora Beatriz Góis Dantas. Pouco tempo depois, o local é destituído de sua funcionalidade e o Núcleo é transferido para uma sala do Hotel Palace,
} 
configurou-se enquanto um órgão suplementar vinculado à PróReitoria de Extensão e Assuntos Comunitários da Universidade Federal de Sergipe (UFS), ocupando até 2013 um prédio histórico, situado em Aracaju, representativo do ecletismo arquitetônico sergipano.

O Artigo 3으, Capítulo 2, da Resolução 07/2000/CONSUUFS, conferiu as diretrizes de funcionamento da instituição, à saber:

I - contribuir para o entendimento do homem sergipano, a partir de suas diferentes formas de

sendo mais tarde transferido para o antigo prédio da Faculdade de Ciências Econômicas na Praça Camerino. Nesse espaço as professoras Hélia Barreto e Verônica Nunes retomam o contato com a professora Cristina Bruno, coincidindo com o momento da publicação do livro "Textos para a História de Sergipe" (um livro de autoria de professores dos Departamentos de História e Ciências Sociais, coordenado por Diana Maria de Faro Leal Diniz, com textos de Beatriz Góis Dantas, Diana Maria de Faro Leal Diniz, Lenalda Andrade Santos, Maria Andrade Gonçalves, Maria da Glória Santana de Almeida e Teresinha Alves de Oliva) aproveita-se para se organizar o projeto museológico que seria responsável pela criação do Museu do Homem Sergipano, inaugurado em 1996. Entretanto as portarias ainda em vigor eram do Museu de Antropologia e somente com a resolução 07/2000/Consu de 28 de abril o museu é oficialmente reconhecido como Museu do Homem Sergipano. No período da Sala de Cultura Popular a professora Hélia Maria de Paula Barreto foi diretora, mais tarde o professor Luiz Alberto assume a direção do Museu de Antropologia, na década de 1990 a 2004 ocorre o retorno da professora Hélia Maria de Paula Barreto à direção, de 2005 a junho de 2009, assume a direção a professora Terezinha Alves de Oliva (DHI) e de junho de 2009 até 2012 assume a professora Verônica Nunes (NMS) (SILVA, 2012:35).

${ }^{2} \mathrm{Na}$ época o Campus contava com cinco cursos: Bacharelado em Arqueologia, Bacharelado em Arquitetura, Licenciatura em Dança, Bacharelado em Museologia e Licenciatura em Teatro. Em 2014, devido à problemas de segurança na cidade envolvendo os cursos noturnos, a Licenciatura em Teatro foi transferida para o Campus matriz da UFS na cidade de São Cristóvão, decidindo não mais retornar ao seu local de origem. Hoje há somente quatro cursos de graduação no Campus Laranjeiras que fica há aproximadamente 20 Km da capital Aracaju. 
adaptação e fazeres culturais, por meio de três grandes setores de atividades técnico-científicas: identificação/estudo das referências patrimoniais, salvaguarda e comunicação das mesmas;

II - contribuir, enquanto órgão de extensão, para a educação popular, a partir do franqueamento de suas exposições ao público, promoção de cursos, conferências, palestras, simpósios, publicações ou qualquer outro mecanismo que permita a democratização de suas coleções e pesquisas;

III - efetuar, sistematicamente, o resgate cultural do Homem sergipano, a partir da documentação e registro dos múltiplos traços materiais e espirituais, da sua cultura;

IV - cuidar da salvaguarda, conservação, registro, ordenação e restauração de suas coleções e outros elementos patrimoniais, bem como estabelecer uma política para constituição de novas vertentes de seu acervo;

$\mathrm{V}$ - manter permanentemente em exposição, parte de seu acervo, além da promoção de exposições temporárias;

$\mathrm{VI}$ - organizar e manter uma Biblioteca especializada, a qual será aberta a pesquisadores e ao público em geral; e

VII - promover a pesquisa mediante ações interinstitucionais e interdepartamentais; sempre em consonância com o conteúdo científico que norteará as políticas do museu.

Parágrafo Único: Manter os respectivos arquivos dos documentos e reserva técnica das coleções.

Os dados que compuseram sua exposição de longa duração - suspensa em 2013 - foram extraídos do livro "Textos para a História de Sergipe" (1991), uma coletânea coordenada pela professora Diana Maria de Faro Leal com artigos de professores de História, Sociologia e Antropologia, imiscuindo-se 
a cultura material oriunda de pesquisas nos campos da Antropologia, Arqueologia, Geografia, Economia e Agronomia.

Em 2010, a então diretora do MUHSE, profa. Ms. Verônica Nunes, ressaltava em um artigo na Revista Patrimônio e Memória (2010:69-82) a sina que acompanhou grande parte das instituições culturais em Sergipe, à exemplo do Arquivo Público do Estado, da Biblioteca Pública e do Colégio Atheneu, com sucessivas mudanças de sedes e denominações. No caso do MUHSE, foi antes Museu de Antropologia (MUSA), Sala de Cultura Popular e posteriormente Museu do Homem Sergipano. Aguardando desde 2013, mais uma mudança em sua nomeclatura e localização.

Tabela 1: Cronologia de "vida, morte e ressurreição" do Museu do Homem Sergipano (MUHSE)

\begin{tabular}{|c|c|c|}
\hline Nomenclatura & Ano inicial & $\begin{array}{c}\text { Ano de } \\
\text { encerramento }\end{array}$ \\
\hline $\begin{array}{c}\text { Museu de } \\
\text { Antropologia (MUSA) }\end{array}$ & 1978 & 1983 \\
\hline $\begin{array}{c}\text { Sala de Cultura } \\
\text { Popular }\end{array}$ & 1983 & 1988 \\
\hline Núcleo Museológico & 1988 & 1991 \\
\hline $\begin{array}{c}\text { Museu do Homem } \\
\text { Sergipano (MUHSE) }\end{array}$ & 1996 & 2013 \\
\hline
\end{tabular}

Fonte: Tabela elaborada por JCM com base nas informações de NUNES, 2010:69-82.

Mas, de acordo com Nunes (2010:70), apesar dos problemas, o museu encontrou sua vocação na "[...] ação educativa voltada para o público escolar, e a intenção de subsidiar os professores com discussões, informações e material didático necessário para sua atuação em sala de aula". Tornando-se assim, um ponto de referência para aqueles que desejavam aprender mais e melhor sobre a história, a 
arqueologia, a arte, a cultura local de matrizes indígenas, africanas, portuguesa que conformaram o "homem sergipano".

O objetivo desse trabalho, em meio ao processo de ressignificação pelo qual o MUHSE passa desde 2014 - quando foi retomado o diálogo entre professores de vários departamentos, Reitoria e Pró-Reitoria de Extensão e Assuntos Comunitários da UFS - pretende historicizar os processos desenvolvidos na instituição entre os anos de 2009 e 2013, momento de criação (2007) e consolidação (2009-2013) do curso de Museologia da UFS vinculando-o ao museu como laboratório de estágio para montagem de exposições, pesquisa, conservação preventiva, realização de eventos e oficinas, enfim, diversas atividades que mostraram a relevância de um "lugar de memória" (NORA, 1993) que beira agora ao esquecimento.

Considerando as reflexões de Paul Ricoeur (2003: 3), norteamo-nos pela idéia de que a "representação do passado" presente no MUHSE quer enquanto guardião de um acervo de memória, quer enquanto objeto da própria memória institucional contém "[...] a presença, a ausência, a anterioridade. Para o dizer de outra forma, a imagem-recordação está presente no espírito como alguma coisa que já não está lá, mas esteve".

O museu apresenta-se como um "remanescente", cuja definição nos dicionários de Língua Portuguesa, remonta "aquilo que ficou, que restou, que sobrou" coaduna-se com o segundo objetivo que visa problematizar a proposta de uma ressignificação particularizada do museu, que será explicitada ao longo do texto, revelando-se antagônica aos princípios da Nova Museologia ou Museologia Social, da qual, um grande grupo de museólogos brasileiros são tributários.

O MUHSE e sua vida entre 2009 e 2013: historicizar para não esquecer. 
O exercício de historicizar algo é muito caro aos historiadores quando a memória começa a padecer do esquecimento como princípio, seja por descaso ou manipulações políticas. A história de uma instituição imiscuída na alternância de pessoas em cargos de poder e alterações significativas no processo de gestão cultural vive em sobressaltos, em meio à escritas e reescritas de um passado que se pretende "postegar como posse", como indicação de "grande feito" daquele grupo que naquele momento se faz status quo. A universidade é pois, uma arena de jogos de interesses, de contestações e tentativas acadêmica e social disciplinadoras e burocratizadoras de vidas e pessoas. Nessa perspectiva, um museu que dela emana absorve para si seus percalços, ônus e bônus.

Assim, a história recente dessa instituição começa com dois atos da Reitoria, na gestão do Prof. Dr. Josué Modesto dos Passos Subrinho, personificados primeiro pela Portaria № 1525, de 18 de junho de 2009, publicada em Diário Oficial da União, cujo Art.1을 resolve "Exonerar, a pedido, o Professor Adjunto, Nível 4, Terezinha Alves de Oliva, do Cargo de Direção CD-4, de Diretor do Museu do Homem Sergipano-MUHSE". Segundo, pela Portaria no 1527, de 18 de junho de 2009, também publicada em D.O.U., cujo Art.1을 resolve "Nomear Professor Assistente, Nível 4, Verônica Maria Meneses Nunes, Matrícula Siape [sic], em regime de trabalho de Dedicação Exclusiva, lotado no Campus de Laranjeiras, para exercer o Cargo de Direção CD-4, de Diretor do Museu do Homem Sergipano-MUHSE". Tais ações são previstas no Art. 9․, II, da Lei 8.112, de 11 de dezembro de 1990.

Nesse ano metade do corpo docente efetivo do Bacharelado em Museologia da UFS ingressou via concurso público, incluindo duas museólogas doutoras. Esse processo ocorreu entre fevereiro e agosto de 2009, com a posse dos professores aprovados. Em julho de 2009 o Campus ${ }^{3}$ muda-se da

\footnotetext{
${ }^{3}$ Na época o Campus contava com cinco cursos: Bacharelado em Arqueologia, Bacharelado em Arquitetura, Licenciatura em Dança, Bacharelado em
} 
escola estadual (CAIC) na qual se instalara desde 2007 para sua sede atual, os casarões oitocentistas que formavam o antigo Quarteirão dos Trapiches, após passar por um processo de restauração da edificação em uma parceria do Projeto Monumenta, do Instituto do Patrimônio Histórico e Artístico Nacional (Iphan) do governo federal, do governo do Estado de Sergipe e da Prefeitura de Laranjeiras.

Nesse período a professora Terezinha Alves de Oliva assumiu a chefia da 8 $^{a}$ Superintendência do Iphan-SE e a professora Verônica Maria Meneses Nunes, naquele momento vice-diretora do MUHSE e Coordenadora do Bacharelado em Museologia da UFS, foi designada diretora do museu. Algo justo, tendo em vista que a professora Verônica Nunes dedicou quase uma vida às pesquisas e trabalhos como museóloga naquela instituição, além de ser responsável por grande parte da expografia de importantes instituições museais de Sergipe, à saber: Museu Galdino Bicho do Instituto Histórico e Geográfico Sergipano (IHGSE), Instituto Dom Luciano, Museu de Anatomia da UFS (Campus São Cristóvão), dentre outros.

O acervo do museu em sua exposição de longa duração, até 2011, esteve distribuído por módulos temáticos: 1.Território Sergipano, 2. A Ocupação Primitiva do Território, 3. A Conquista do Território e da População, 4. A Organização do Trabalho: a importância da mão-de-obra sergipana, 5. Evidências de um Processo Histórico Dependente: a cultura do açúcar, 6. Evidências de um Sergipe em Desenvolvimento, 7. As Estruturas de Poder que Moldaram a Sociedade, 8. A República Brasileira e Sergipe, 9. As Formas de Representação da Cultura Sergipana.

Museologia e Licenciatura em Teatro. Em 2014, devido à problemas de segurança na cidade envolvendo os cursos noturnos, a Licenciatura em Teatro foi transferida para o Campus matriz da UFS na cidade de São Cristóvão, decidindo não mais retornar ao seu local de origem. Hoje há somente quatro cursos de graduação no Campus Laranjeiras que fica há aproximadamente 20 Km da capital Aracaju. 


\section{Imagem1: Planta Baixa do MUHSE}
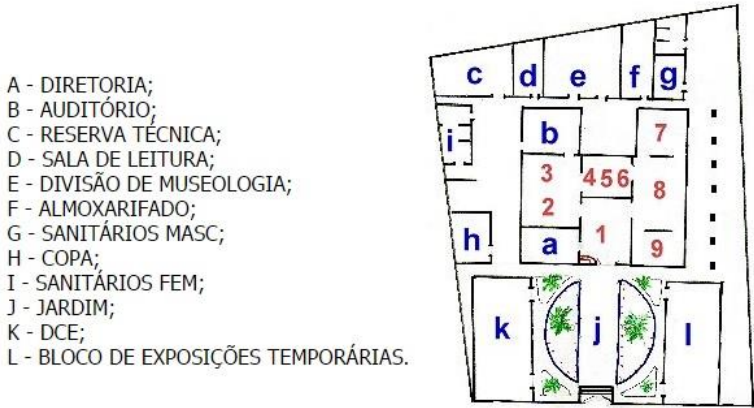

Planta do Museu

Fonte: Disponível em: http://www.aracaju.com/museu/ apresentacao.htm, Consultado em 29/03/2015.

A professora Dra. Maria Cristina Bruno (MAE/USP) esteve várias vezes em Sergipe compartilhando seus conhecimentos na área da Museologia tanto no Museu de Arqueologia do Xingó (MAX) quanto no MUHSE, ministrando cursos sobre "Herança Cultural: as possibilidades do tratamento museológico", "Etapas para a elaboração de exposição", "Museologia: as perspectivas da nova Museologia" (NUNES, 2010:75-76), além de colaborar nos projetos expográficos da UFS. Sobre sua experiência junto ao MUHSE, afirmou em 1999:

Este projeto tem na sua origem, a experiência de muitos anos do Museu de Antropologia da Universidade Federal de Sergipe, que sempre pautou sua atuação com exposições instigantes, baseadas em problemas concretos da sociedade sergipana. Procurou-se extrair do processo histórico os elementos que sustentam as particularidades de uma sociedade que ao longo dos séculos conviveu com concentração de terras e uma estrutura produtiva agrária, que foi coadjuvante da dizimação indígena e da opressão sobre o negro, que tem sua elite envolvida pela cultura literária e bacharelesca ao mesmo tempo em que as 
camadas menos privilegiadas da população se expressam através da oralidade e do artesanato. Essas características que aparecem em muitas regiões brasileiras, assumem um contorno especial em Sergipe e esta exposição procurará discutir esse tema (Disponível em: http://www.aracaju.com/museu/apresentacao.htm, Acesso em: 29/03/2015).

Dez anos depois, com o ingresso de novo professores efetivos na UFS e tendo à frente da direção do museu a professora que auxiliara no processo de implantação do Bacharelado em Museologia em Sergipe, várias atividades universitárias envolvendo grupos cadastrados no Diretório de Grupos de Pesquisa do Conselho Nacional de Desenvolvimento Científico e Tecnológico (CNPq) começaram a ser desenvolvidas, ao lado das já tradicionais ações que o MUHSE realizava conforme seu calendário semestral.

Em 2009, sob a coordenação do Prof. Dr. Samuel Barros de Medeiros Albuquerque, foi realizado o Seminário Semestral 2009/2ㅇ do Grupo de Estudos e Pesquisas em História das Mulheres (GEPHIM/CNPq) com o tema "Educação das Mulheres: história, memória e musealização". Ainda nesse ano foi organizado pela professora Dra. Cristina de Almeida Valença Cunha Barroso o "I Ciclo de palestras de Educação Especial em Museus Deficiência, educação e Museus: os problemas da acessibilidade".

Em 2010, a professora Dra. Cristina de Almeida Valença Cunha Barroso realizou o "I Ciclo de Palestras Cultura, Museus e Patrimônio sergipano". No mesmo ano, sob a coordenação da professora Dra. Janaina Cardoso de Mello, realizou-se a "I Jornada Científica do Grupo de Estudos e Pesquisa em Memória e Patrimônio Sergipano (GEMPS/CNPq) e do Grupo de Estudos e Pesquisas de História das Mulheres (GEPHIM): Instituições museais e a patrimonialização das fontes sergipanas" onde alunos dos cursos de Museologia, História, Ciências Sociais e 
outros, da UFS e outras instituições de ensino superior privadas, apresentaram projetos de pesquisa de suas monografias e/ou bolsas de Iniciação Científica, Extensão e Inovação Tecnológica.

Em 2011, foi realizada a "Oficina de extensão Técnicas de Scrapbooking para montagem de exposicao com fotografias" sob a coordenação da professora Dra. Cristina de Almeida Valença Cunha Barroso.

Imagens 2 e 3: Oficina de extensão Técnicas de Scrapbookingno MUHSE
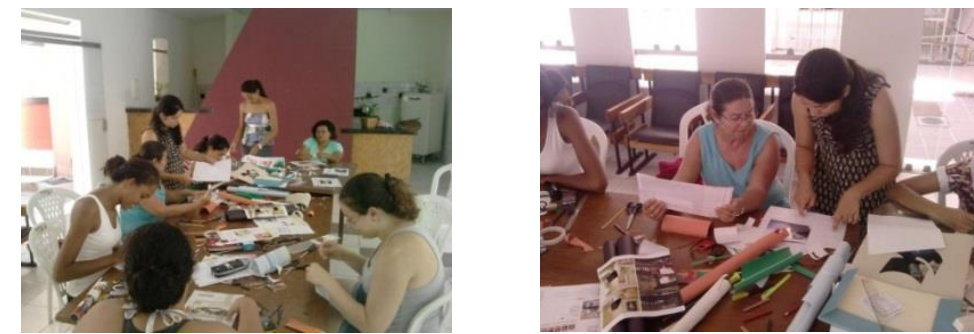

Fotos: JCM (2011).

Ainda em 2011, o GEMPS/CNPq realizou sob a coordenação da professora Dra. Cristina de Almeida Valença Cunha Barroso o "Il Ciclo de Educação Especial em Museus" ofertando palestras e Oficinas de Braile e Libras.

Imagens 4 e 5: Oficinas de Libras e Braile.
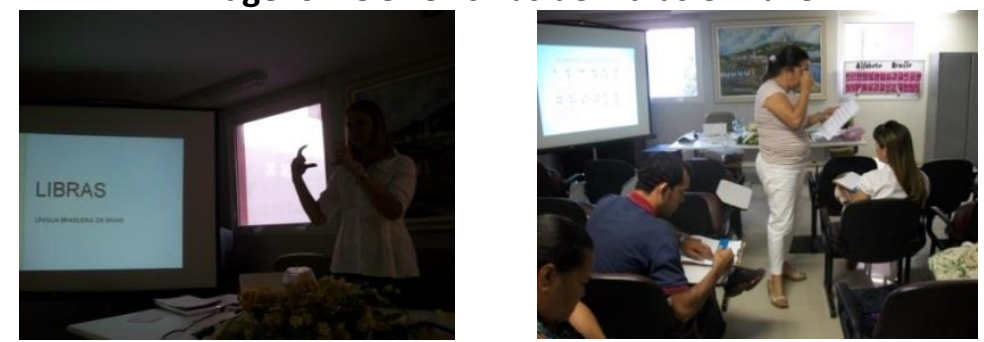

Fotos: JCM (2011).

Monografias do Bacharelado em Museologia usaram o MUHSE ou seu acervo como tema de pesquisa, além de monografias dos cursos de História, Arqueologia e Sociologia. 
Em 2012, com a greve das universidades federais e tendo vários alunos concludentes já aprovados em concurso público para museólogo do município de Palmeira dos Índios/AL, foi aprovada em documento emitido pela ASDUFS a realização das bancas de defesa das monografias do Bacharelado em Museologia da UFS no auditório do MUHSE.

Imagens 6 e 7: Defesas de Monografia do Bacharelado em Museologia UFS (Luis Constantino e Benedito Letrado)
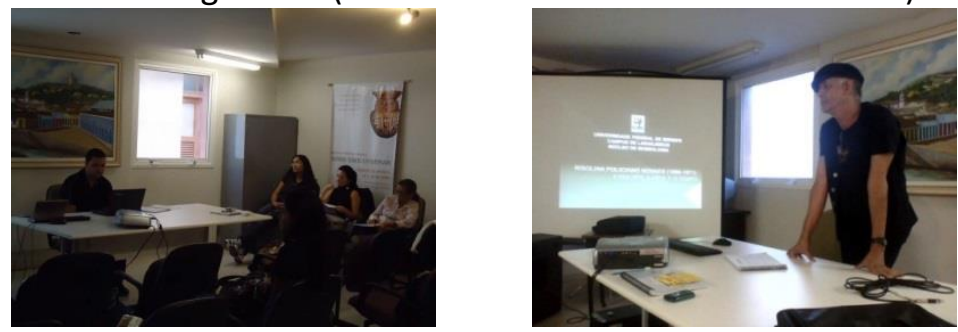

Fotos: VS e JCM (2012).

No mesmo ano o MUHSE, em parceria com a Biblioteca Pública Epifânio Dória realizou o "Seminário Aracaju e seu patrimônio", com palestras sobre a memória e o patrimônio, a cidade e o patrimônio e o patrimônio de Aracaju. Culminando com a palestra e exposição de Bené Santana nas instalações do museu.

Imagens 8 e 9: Exposição do artista plástico Bené Santana no MUHSE (2012)
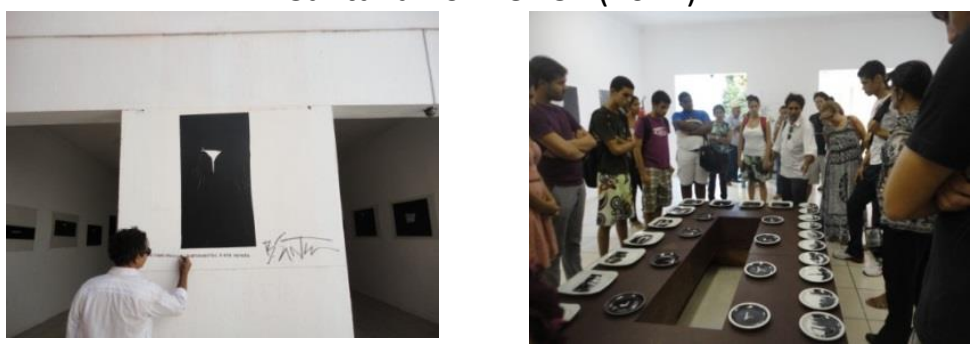

Fonte: Disponível em: http://museudohomemsergipano. blogspot.com.br/ , Consultado em 29/03/2015. 
Trabalhos com bolsas de Iniciação Científica (PIBIC), Extensão (PIBIX) e Inovação Tecnológica (PIBITI) foram desenvolvidos com base no acervo acondicionado no MUHSE, dentre eles, alguns resultaram em publicações, à saber:

Tabela 2: Trabalhos acadêmicos com base no acervo do MUHSE

\begin{tabular}{|c|c|c|c|}
\hline Título & Autor & $\begin{array}{c}\text { Evento, local e } \\
\text { data }\end{array}$ & Orientador \\
\hline $\begin{array}{l}\text { Arqueo-Digital 360: } \\
\text { tecnologia 3D-Bin } \\
\text { aplicada ao } \\
\text { acervo arqueológico } \\
\text { do Museu do Homem } \\
\text { Sergipano (MUHSE) }\end{array}$ & $\begin{array}{l}\text { Profa. Dra. Janaina } \\
\text { Cardoso de Mello }\end{array}$ & $\begin{array}{l}\text { I Semana de } \\
\text { Arqueologia - } \\
\text { Unicamp “Arqueol } \\
\text { ogia e Poder", } \\
\text { UNICAMP- } \\
\text { Campinas, } 2013 . \\
\end{array}$ & - \\
\hline $\begin{array}{l}\text { Véritas Mouseion 3D - } \\
\text { Acervos Expositivos do } \\
\text { Museu do Homem } \\
\text { Sergipano } \\
\text { com rotação em 360ㅇ }\end{array}$ & $\begin{array}{l}\text { Romário Rodrigues } \\
\text { Portugal (Bolsista } \\
\text { PIBITI-UFS). }\end{array}$ & $\begin{array}{l}\text { IV Encontro de } \\
\text { História da Ufal, } \\
\text { UFAL - Maceió, } \\
2012 .\end{array}$ & $\begin{array}{l}\text { Profa. Dra. } \\
\text { Janaina } \\
\text { Cardoso de } \\
\text { Mello }\end{array}$ \\
\hline $\begin{array}{l}\text { Véritas Mouseion- } \\
\text { Uma Experiência } \\
\text { Além-Muros através } \\
\text { de Oficinas em } \\
\text { Instituições Culturais } \\
\end{array}$ & $\begin{array}{l}\text { Irla Suellen da } \\
\text { Costa Rocha } \\
\text { (Bolsista PIBIX) }\end{array}$ & $\begin{array}{l}\text { XVI Encontro } \\
\text { Regional de } \\
\text { História da Anpuh- } \\
\text { Rio, Rio de } \\
\text { Janeiro, } 2014 . \\
\end{array}$ & $\begin{array}{l}\text { Profa. Dra. } \\
\text { Janaina } \\
\text { Cardoso de } \\
\text { Mello }\end{array}$ \\
\hline $\begin{array}{l}\text { Controle de cupins em } \\
\text { peças históricas de } \\
\text { madeira do Museu do } \\
\text { Homem Sergipano } \\
\text { Utilizando Atmosfera } \\
\text { Modificada }\end{array}$ & $\begin{array}{l}\text { T. M. S. Souza ; L. C. } \\
\text { Paz ; J. S. Sá ; G. S. } \\
\text { Rolim ; M. E. } \\
\text { Correia Oliveira ; G. } \\
\text { T. Ribeiro }\end{array}$ & $\begin{array}{l}\text { Artigo Revista } \\
\text { Scientia Plena, } \\
\text { Vol. 8, Num. 4, } \\
2012 .\end{array}$ & - \\
\hline
\end{tabular}

Fonte: Tabela elaborada por JCM (2015)

Ao longo de seu funcionamento o MUHSE desenvolveu ações integrantes do "Projeto de Documentação e Memória", com pesquisa do acervo para a montagem de exposições e no "Projeto Museu-Escola" relacionado à dois subprojetos: "O Museu é o Palco", com a participação da Cia. Eu sou seu fã, toche e "Museu também é lugar de criança", ambos com visita guiada, teatro de bonecos e oficinas com crianças (NUNES, 2010:82). 
Imagens 10 e 11: Acervo Arqueológico do MUHSE
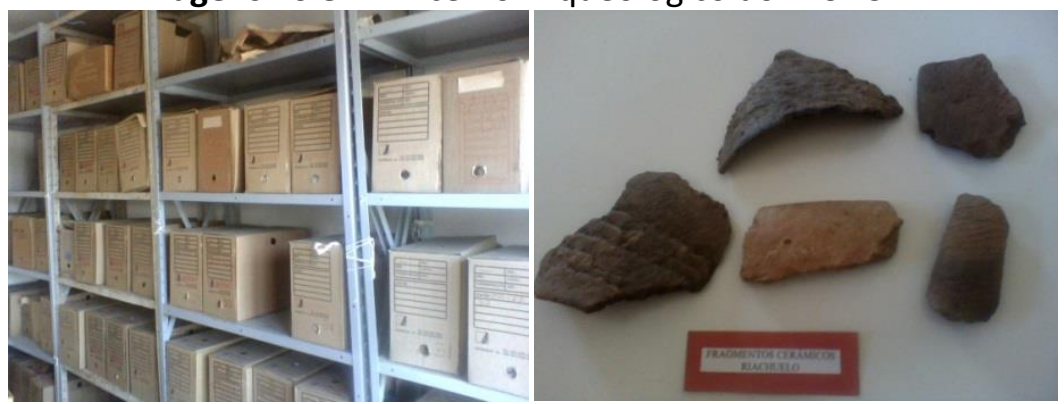

Fotos: JCM (2013).

O acervo do MUHSE possuía uma rica coleção de cerâmicas, fotografias, pinturas, livros, entre outros objetos. No que tange à cultura material arqueológica havia aproximadamente 60 caixas contendo fragmentos cerâmicos e ósseos, lascas de quartzo, porcelanas e faianças dos séculos XIX e $X X$, resultante dos salvamentos arqueológicos realizados entre as décadas de 1980 e 1990 nos municípios de Riachuelo, Santo Amaro das Brotas, Porto da Folha, dentre outros que evidenciam a presença da tradição cerâmica Aratu, estudada pelo antigo Núcleo de Pesquisa Arqueológica (NPA) (MELLO, 2013:2).

O MUHSE enquanto remanescente do esquecimento no processo de ressignificação anunciado.

Em 02 de maio de 2011, o museu foi fechado à visitação pública pela Prefeitura do Campus em razão da deterioração dos edifícios com infiltrações, goteiras, rachaduras nas paredes e na lage, queda do reboco do teto e paredes sem que houvesse o investimento na manutenção preventiva ou reparadora, levando à desmontagem da exposição de longa duração para salvaguardar os objetos museológicos expostos e a vida humana que por ali transitava. Mesmo assim, o prédio anexo continuou em funcionamento para a realização de exposições temporárias e eventos de pequeno porte envolvendo 
a comunidade universitária. Em 2012, a interface muhse.ufs.br (na homepage da UFS) informa que foram iniciadas reuniões e estudos para a elaboração de projectos de restauração e reforma, luminotécnico, elétrico, hidráulico, além da adaptação do projecto museográfico e expográficos ao prédio.

Todavia, a Portaria no 1986 de 31 de maio de 2013 fechou indefinidamente as portas da instituição, quando ao art. 10 cumpria "Exonerar, a pedido, o Professor Assistente, Nível 02, Verônica Maria Meneses Nunes, Matrícula SIAPE [sic], em regime de trabalho de Dedicação Exclusiva, lotado no Núcleo de Museologia do Campus de Laranjeiras - NMS/CAMPUSLAR, do Cargo de Direção CD-4, de Diretor do Museu do Homem Sergipano da Pró-Reitoria de Extensão e Assuntos Comunitários MUHSE/PROEX".

Apesar da sinalização ainda indicar o museu na rua de Estância, 228, em Aracaju, irônicamente parte do acervo do MUHSE voltou ao seu local de origem, entre 1983 e 1988, sendo embalado e armazenado em duas salas do Centro de Cultura e Arte/UFS-CULTART, na rua Ivo do Prado. O material arqueológico foi entregue ao Laboratório do Bacharelado em Arqueologia da UFS situado no Campus Laranjeiras. Enquanto fragmentos de imagens, projetos e depoimentos sobre a experiência de fruição cultural junto ao MUHSE no período de seu funcionamento ainda se encontram dispersos na internet.

Imagens 12 e 13: O MUHSE fechado indefinidamente.
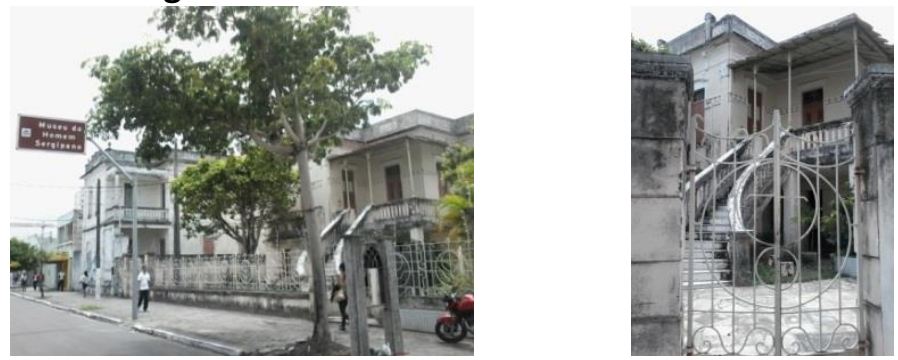

Fotos: JCM (2015). 
Ainda hoje é possível mapear nove locais online de referência sobre o MUHSE:

Tabela 3: O MUHSE online

\begin{tabular}{|c|c|}
\hline Nome/mantenedor & Site ou blog \\
\hline $\begin{array}{l}\text { Interface do MUHSE na } \\
\text { homepage da UFS. }\end{array}$ & http://muhse.ufs.br/ \\
\hline Aracaju Web Design Ltda. & $\begin{array}{l}\text { http://www.aracaju.com/museu/apresentacao.h } \\
\underline{\operatorname{tm}}\end{array}$ \\
\hline $\begin{array}{l}\text { Blog Museu do Homem } \\
\text { Sergipano }\end{array}$ & $\begin{array}{l}\text { http://museudohomemsergipano.blogspot.com. } \\
\mathrm{br} /\end{array}$ \\
\hline $\begin{array}{l}\text { Blog Uma nova História/ } \\
\text { Daniel Max (graduado em } \\
\text { História) }\end{array}$ & $\frac{\text { http://newcrisdanistory.blogspot.com.br/2012/1 }}{\text { 2/visita-ao-museu-do-homem-sergipano.html }}$ \\
\hline $\begin{array}{c}\text { Reino de Clio - visita } \\
\text { virtual pelo } \\
\text { MUHSE/Marcelo Eduardo }\end{array}$ & http://reino-de-clio.com.br/MUHSE.html \\
\hline $\begin{array}{l}\text { Matéria jornalísitca de } \\
\text { Fernando Araújo/F5 } \\
\text { News. }\end{array}$ & $\begin{array}{l}\text { http://www.f5news.com.br/6207 museu-do-- } \\
\text { homem-sergipano-patrimonio-publico-que- } \\
\text { deve-ser-preservado-.html }\end{array}$ \\
\hline $\begin{array}{c}\text { Homepage Museus em } \\
\text { Sergipe no Link Museu do } \\
\text { Homem/Prof. Msc.Fábio } \\
\text { Figueirôa } \\
\end{array}$ & http://www.infonet.com.br/museusemsergipe/ \\
\hline $\begin{array}{l}\text { Museus de Sergipe/Profa. } \\
\text { Dra. Janaina Mello (DMS- } \\
\text { UFS) }\end{array}$ & https://sites.google.com/site/museusdesergipe/ \\
\hline $\begin{array}{c}\text { Blog Coleção } \\
\text { Carrapicho/Museóloga } \\
\text { Valdineide Silva }\end{array}$ & http://colecaocarrapicho.wordpress.com \\
\hline
\end{tabular}

Fonte: Tabela elaborada por JCM (2015)

Por isso, a palavra "remanescente" como aquele fragmento que subsiste do que já foi um dia "um todo", algo completo, mas que agora é apenas uma sombra, pode ser perfeitamente aplicável à realidade desse museu. Particionado, encaixotado, silenciado, permanece nos "porões institucionais" 
enquanto discutem seu destino na morosidade do tempo e da baixa orçamentária.

Diante da consternação de alunos e docentes da UFS, da ausência de um espaço cultural que servia à comunidade acadêmica, escolar e turística, a Portaria $n^{\circ} 1631$ de 31 de julho de 2014, resolveu em seu Art.1으 designar como membros do Grupo de Trabalho do Museu do Homem Sergipano da Universidade Federal de Sergipe seis representantes, à saber: professores dos departamentos de História, Arqueologia, Museologia, Artes Visuais e Design, do Museu de Arqueologia do Xingó presididos pela Pró-Reitora de Extensão.

Posteriormente a Portaria no 2087 de 02 de outubro de 2014, também emitida pelo reitor em exercício Prof. Dr. André Maurício Conceição de Souza, resolveu em seu Art. 1으 “Designar o Professor Associado, Nível 02, Maria da Conceição Almeida Vasconcelos, Matrícula SIAPE [sic], em regime de trabalho de Dedicação Exclusiva, lotado no Departamento de Serviço Social do Centro de Ciências Sociais Aplicadas DSS/CCSA, com exercício de suas funções de Pró-Reitora de Extensão - PROEX, para responder, cumulativamente, pela função de Coordenador do Museu do Homem Sergipano".

Recentemente, já no início de 2015, a atual Coordenadora do Departamento de Museologia da UFS, noticiou em reunião de Colegiado para colegas docentes e representante discente que fora incubida da elaboração do Plano Museológico do MUHSE. Isso causou estranhamento, tendo em vista que embora a profissional possua reconhecida competência técnica e formação na área museológica, a mesma se encontra há menos de dois anos em Sergipe, vinda por redistribuição de vagas de uma universidade em outra região da federação. Ou seja, não possuiu a vivência cotidiana do museu com alunos e professores, não obteve o conhecimento do conteúdo extrovertido em exposições de longa e curta duração, das experiências realizadas em torno do fazer acadêmico (pesquisa, extensão e inovação 
tecnológica) e por isso intenciona recriar um "novo museu" apenas como um simulacro do passado, com uma "tradição inventada" - cuja própria nomeclatura está fadada a mudar para que "a instituição não seja mais confundida com o Museu da Gente Sergipana", inaugurado em 2011, com localização e proposta museológica distintas.

Nesse caso, diferentemente das outras vezes, em que o nome da instituição foi alterado mas sua essência permaneceu, sendo sua reconfiguração acompanhada por aqueles que partilharam de sua trajetória de fundação e consolidação, a proposta atual termina por lançar no esquecimento "o que foi" para empenhar-se "no que será", muitas vezes repetindo ações passadas sem dar-lhes os devidos créditos no afã de apresentálas como "novidade" sob uma determinada "autoria" do presente.

Diante dessa ressignificação de direcionamento museal, sobretudo dessa ressemantização da própria instituição, questiona-se a forma como os princípios da Nova Museologia ou da Museologia Social poderiam servir como bússola para apontar o horizonte. Tendo em vista que os mesmos difundem a coexistência dialógica tripartite entre o museu institucional, o acervo material que lhe dá sentido e a comunidade que lhe dá significado. Pois, em afinidade com a Declaração de Santiago (1972):

[...] o museu é uma instituição ao serviço da sociedade da qual é parte integrante e que possui em si os elementos que the permitirem participar na formação da consciência das comunidades que serve; que o museu pode contribuir para levar essas comunidades a agir, situando a sua actividade no quadro histórico que permite esclarecer os problemas actuais (MOUTINHO, 1993: 7-8).

Nesse caso, o mais justo, antes da elaboração de qualquer plano museológico isolado seria convidar os moradores 
de Aracaju, principalmente aqueles residentes no entorno do prédio ocupado entre 1996 e 2013, os estagiários, alunos, professores e gestores que mantiveram uma profunda relação com o museu durante esse período para simplesmente "escutar a voz social" que poderia advir daí. Dividir as responsabilidades, compartilhar as decisões, empoderar a coletividade, socializar impressões, chamando todos à ressurreição do "novo/velho museu". Nesse sentido, qualquer relação de poder hierárquica seria diluída e o personalismo individualista transformado em uma rede de solidariedade cultural. Haveria aí uma real poética museológica.

Infelizmente, não é isso que está acontecendo. $\mathrm{O}$ "museu remanescente" está sendo discutido entre quatro paredes, à portas fechadas, por um grupo de intelectuais que depois tratará de "publicizar" o resultado de "seus feitos" no soerguimento do "novo museu" ao resto da comunidade, que mais uma vez assistirá "bestializada", no auditório talvez, a indicação da contemplação de algo que lhe é proposto sem qualquer identificação subjetiva ou participação efetiva. Por isso, mais uma vez remontando-nos à Paul Ricoeur (2003: 7), quando:

Falamos de reapropriação do passado histórico, é preciso falarmos igualmente da privação dos atores do seu poder originário, o de narrarem-se a eles próprios. É difícil destrinçar a responsabilidade pessoal dos atores individuais, da das pressões sociais que trabalham subterraneamente a memória colectiva. Essa privação é responsável por esta mistura de abuso de memória e de abuso de esquecimento (grifo nosso).

Em pleno século XXI, depois de terem sido debatidos ardorosamente os documentos de Santiago do Chile (1972), Quebec (1984) e Caracas (1992), por um renomado grupo de partícipes da área museológica, elaborando importantes textos e 
ações no curso de uma efetiva Museologia Social envolvendo Mário Moutinho, Mário Chagas, Maria Cristina Bruno, Marília Xavier Cury, Maria Célia Teixeira, dentre outros, observa-se na UFS, em Sergipe, um retrocesso e pior, para que alguns brilhem fulgurosamente por cinco minutos, o obscurantismo estará recaindo prolongadamente sobre aqueles que durante décadas mantiveram a instituição servindo ao público com a realização de exposições, eventos, oficinas e pesquisas, à despeito da ausência das verbas necessárias, mas acreditando naquele espaço como um vetor identitário de vidas de homens, mulheres, crianças sergipanas de nascimento ou de afinidade.

Entre a memória e o esquecimento, não seria melhor se a salvaguarda do patrimônio realizasse as atualizações necessárias com o passar do tempo e transformações da sociedade sergipana, respeitando a contribuição de discentes, docentes, visitantes, gestores e vizinhos ao espaço museal? Afinal, "novos museus" podem ser ocos de sentido e afinidade se não forem sensíveis as raízes de seus usuários.

\section{Referências Bibliográficas:}

DINIZ, D. M. F. L. (Coord.). (1991). Textos para a História de Sergipe. Aracaju: EDUFS/BANESE.

MELLO, J. C. (2013). Arqueo-Digital 360\%: tecnologia 3D-Bin aplicada ao acervo arqueológico do Museu do Homem Sergipano (MUHSE). Anais I Semana de Arqueologia da Unicamp "Arqueologia e Poder", Edição Especial, 1-16. Disponível em

http://www.nepam.unicamp.br/arqueologiapublica/revista/anai s/arqueologia-patrimonio-e-turismo/PDFs/arquivo7.pdf, Consultado em 20/10/2014]. 
MOUTINHO, M. (1993). Sobre o conceito de Museologia Social. Cadernos de SocioMuseologia, 1, (1), 7-9. [Disponível em http://revistas.ulusofona.pt/index.php/cadernosociomuseologia/ article/view/467/370, Consultado em 04/04/2015].

NORA, P. (1993). Entre história e memória: a problemática dos lugares. Revista Projeto História,10, 7-28.

NUNES, V. M. M. (2010). O Museu do Homem Sergipano. Revista Patrimônio e Memória, 6, (2), 78-96, [Disponível em http://pem.assis.unesp.br/index.php/pem/article/view/87/556, Consultado em 30/03/2015].

PORTARIA no 1525/2009, de 18 de junho.

PORTARIA no 1527/2009, de 18 de junho.

PORTARIA n ${ }^{\circ} 1631 / 2014$, de 31 de julho.

PORTARIA no 2087/2014, de 02 de outubro.

PORTUGAL, R. R. (2012). Véritas Mouseion 3D -Acervos Expositivos do Museu do Homem Sergipano com Rotação em 360․ Anais Eletrônicos do IV Encontro de História da Ufal. [Disponível

em http://www.ichca.ufal.br/laboratorio/cpdhis/arquivos/anais eletronicos-IV encontro de historia-2012.pdf, Consultado em 20/10/2014].

RESOLUÇÃO 07/2000/CONSU-UFS, 28 de abril.

RICOEUR, P. (2003). Memória, história, esquecimento. [Trad.]. Conferência internacional "Haunting Memories? History in Europe after Authoritarianism". Budapeste. [Disponível em http://www.uc.pt/fluc/lif/publicacoes/textos disponiveis online Lpdf/memoria historia, Acesso em 02/04/2015].

ROCHA, I. S. C. (2014). Véritas Mouseion - Uma Experiência Além-Muros através de Oficinas em Instituições Culturais. Anais 
do XVI Encontro Regional de História da Anpuh-Rio: Saberes e práticas científicas. Rio de Janeiro: USU/ANPUH-Rio. [Disponível em

http://www.encontro2014.ri.anpuh.org/resources/anais/28/140 0346692 ARQUIVO artigolrlaSuellenCostaRochaanpuh2014.pdf, Consultado em 20/12/2014].

SILVA, V. (2012). Coleção Carrapicho: a trajetória das cerâmicas expostas no Museu do Homem Sergipano (1983-2012). Monografia de Graduação. Laranjeiras: Departamento de Museologia da Universidade Federal de Sergipe.

SOUZA, T. M. S, PAZ, L. C., SÁ, J., ROLIM, G. S., CORREIA OLIVEIRA, M. E. \& RIBEIRO, G. T. (2012). Controle de cupins em peças históricas de madeira do Museu do Homem Sergipano Utilizando Atmosfera Modificada. Scientia Plena, 8 (4), 1-4. [Disponível em file:///C:/Users/bom\%20dia/Downloads/14364690-1-SM.pdf, Cosultado em 29/03/2015]. 